\title{
PERFORMANCE ASSESSMENT OF COMMERCIAL PRINCIPLES IN WATER SERVICES PROVISION
}

\author{
DUA'A B. TELFAH ${ }^{1}$, MAHA HALASHEH ${ }^{2}$, LARS RIBBE $^{3} \&$ GIORGIO ROTH ${ }^{1}$ \\ ${ }^{1}$ Department of Civil, Chemical and Environmental Engineering, University of Genoa, Italy \\ ${ }^{2}$ Water, Energy and Environment Centre, University of Jordan, Jordan \\ ${ }^{3}$ Institute for Technology and Resources Management, University of Applied Sciences, Germany
}

\begin{abstract}
As a water scarce country, Jordan started initiatives to reform its water sector to meet the objective of bridging the gap between increasing demands and diminishing renewable water supply, besides implementing technical solutions. Commercialization, as alternative to privatization in its conventional notion, was adopted as a strategy to extend partnership with the private sector and to establish new corporatized water service companies wholly owned by the Government and operated under commercial principles. This paper assesses the utilization of commercial and market principles in managing water services provision, it assesses Amman water utility performances under the management of Jordan water Company (Miyahuna) Corporate and the Management Contractor (LEMA). The assessment covered the period from 1999 through 2013, with 1999 as a base year. It was based on the International Water Association recommended performance indicators and on the customized ones, as used by the Ministry of Water and Irrigation. Financial sustainability Criteria variations and its trends has been analysed, discussed and historically tracked for possible indications and causes. Miyahuna performance was compared to international and regional performance standards using data available on the International Benchmarking Network for Water and Sanitation Utilities database. This inter-utility comparison may trigger enhancement as the water sector direct completion is limited. The paper concludes that application of the corporatize model for the Amman utility was successful. Miyahuna performance in the long term reveals positive trends in most of the evaluated criteria.
\end{abstract}

Keywords: performance assessment, performance indicators, corporatization, financial sustainability.

\section{INTRODUCTION}

Water and wastewater services were used to be provided by public bodies. This was associated with series of problems like poor performance and low productivity [1]. Public awareness was raised in the 1980s about the necessity of introducing the concept of privatization as solution and enhancement tools for service provision [1]. Privatization or different private sector participation (PSP) forms involve the concept of operating and monitoring the water utility by private sector.

Utilizing privatization in water sectors highlighted the importance of the market principles, investment, financial liberalization, decentralization and reduced role of public bodies [2]. Prasad concluded that privatization or different PSP forms usually bring more investment and improve the quality of service.

Increasing the risk of abuse of market is one of arguments used against introducing privatization in water services as monopoly is the common style in operating this industry. Monopoly style is a characteristic of water services in both private and public provision; it may lead to poor service in the public case or increasing water tariff in private case [2].

However, a third practice caught between the two previous practices that the solution can be when considering the water as commercial good and human right [2]. Hence, the concept of corporatization raised as mid solution in which commercial principle to operate the water utility and at the same time the ownership of the utility is related to the public body. 
The utilization of the corporatization will reorient the sector in all aspects and form a new legal and institutional framework. Different improvements and enhancements can be achieved through working under corporatization. This include achieving the operational and financial autonomy, enrichment of accountability and transparency; push the managers and staff to work under the economic criteria, and it will benefit the sector by relieving providers from bureaucratic burdens including the limitations of Civil Servant By-law and complicated procurement procedures [3].

\subsection{Performance assessment}

In 1990's after the concept of Integrated Water Resources Management (IWRM) and Integrated River Basin Management (IRBM) were introduced, many countries started initiatives to assess the water strategy and water sector [4]. Different approaches and methods have been adopted to assess the water sector as Wieriks summarizes in his paper of 2011 [4]. The suitable assessment method depends on the institutional level [5], which differentiates between the operational choice, the collective choice and constitutional choice. Operational choice is conducted usually using key performance indicators and/or Benchmarking approach; the Collective choice usually uses Stakeholder analysis and Social Network Analysis methodologies; while the Constitutional choice is usually used to assess the Dublin principles [4].

Roche et al. [6] mentioned that the best theoretical practice to assess and judge service performance is done by the consumers as they have the ability to judge if the service is satisfactory or not. However, measuring the service performance for public service is not an easy task and that is why different approaches have been developed to conduct the assessment. Alegre and Coelho [7], reported the principle measures used by Sjovold to scale the performance which utilizes performance indicators both quantitatively and qualitatively.

International Benchmarking Network for Water and Sanitation Utilities (IBNET) has been engaged Since 1997 in monitoring water sector development, their engagement was through developing a new scoring system" Apgar" to assess the utility performance based on six criteria: water supply coverage, sewerage coverage, NRW collection period, operating cost coverage ratio, and affordability of water and wastewater services [8].

\subsection{Performance indicators}

Performance indicators approach is a holistic approach to inform the quantitative efficiency or effectiveness measures for water utility [7]. It was introduced to provide objective measurements, encouraging better performance and developing transparency in order to achieve effective service [6].

Key Performance Indicators (KPIs) present a grade that guarantee the performance evaluation of the utility [7]. Good score in one indicator does not present the whole performance of the utility. International Water Association (IWA) developed a system consists of 170 performance indicators which based on 232 variables in order to monitor efficiency and the effectiveness of water utility.

\section{CASE STUDY}

The Hashemite kingdom of Jordan (Jordan) is suffering from limited renewable water resources, arid and semi-arid climate, limited financial resources, and high population growth. The Government of Jordan (GoJ) has identified the water sector including water 
resources management and water and wastewater service provision as one of the most priority areas for investment besides energy.

The potentiality of providing water and wastewater services have been dictated by weak financial position, weak management, geographical and hydrogeological constrains, and social constrains [9].

Ministry of Water and Irrigation (MWI) started different initiatives using different tools and methodologies to overcome these constraints. Several technical approaches were considered including water sector reforms of which the main pillar is commercialization as alternative to privatization in its conventional notion [10].

On $9^{\text {th }}$ January 2007, Water Authority of Jordan (WAJ) signed an Assignment and Development Agreement with Jordan Water Company (Miyahuna), as a limited liability company fully owned by WAJ and formed under laws of Jordan [11]. Miyahuna performance monitoring is assigned to the Performance (Program) Management Unit (PMU). PMU is a unit established within the Ministry of Water and Irrigation to monitor the water and wastewater services provisions and to enhance the application of commercial principles in Jordanian Water Sector.

According to the Articles of Association, Miyahuna (with Limited Liability) has the responsibility of service provision, management and operation, and expanding investment of water and wastewater services in Amman [11]. It owns the mobile assets and revenues generated from the service area; it is responsible for normal investment from its own resources; the company enjoys full independence in terms of managing its budget and revenues.

The importance of this study comes from the size and importance of Miyahuna as main water Service Company serving approximately 4.1 million inhabitants in 2016 (40\% of Jordan population). On the other hand, Assessing Miyahuna performance as a corporatized entity will give directions to decision makers for orienting policies and strategies to achieve better financial sustainability.

\section{METHODOLOGY}

\subsection{Data collection}

LEMA Reports provided data only on the period 2000-2006. Performance Management Unit (PMU) Monitoring reports covered the remaining study period. PMU started documenting its monitoring system including Variables and KPI's as of 2007 after the establishment of Miyahuna. Miyahuna records included the whole period. WAJ reports provided another source of information for the whole studied period as well as providing data for the prior LEMA time. Miyahuna Budget as published on the General Budget Department website under the Government Units Budget Law has been also used as a source of data. The Central Bank of Jordan data for inflation has been also used for calculating the inflation rates since 1999, it provided the necessary data that enabled using 1999 as a base year. In addtion, expert interviews with different stakeholder in the water sector have been carried out.

The data concerning the regional and international utilities performance were generated from the data base of the International Bank for Reconstruction and Development/The World Bank [12]. The benchmarking system known as International Benchmarking Network for Water and Sanitation Utilities (IBNET) was explored and relevant data and information were downloaded from the IBNET website.

The quality control performed on data showed slight discrepancies in the data as it is reported from different institutions, the source of discrepancy partly is coming from the 
different definitions of the same item, other discrepancies revealed to be related to the data status (officially audited or released while under use and work progress by the institutions); the discrepancies were resolved by more indepth understanding of the exact meaning of the data and also by referring to the audited final figures. This required consultation and discussions with the responsible official experts from MWI, Miyahuna, WAJ and PMU.

\subsection{Assessment methodology}

The oficial exvhange rate between Jordan Dinar (JD) and United States Dollar (USD) currencies is used (1.0 JD = 1.41 USD). This research uses Jordan Dinar (JD) in presenting the currency units for compatibility between the different sections of this research. Miyahuna is using JD in its financial statements; international institutions as IBNET publish cost and revenues in United State Dollar Currency (USD).

The assessment and evaluation of Miyahuna performance was carried out by the application of the set of performance indicators (PIs) recommended by the International Water Association (IWA) and used by the Performance Management Unit (PMU) in monitoring and auditing the performance of the water companies in the country. These indicators are considered representative as they gauge the utility adherence to the strategic goals of MWI as well as they give overview of the standing of the utility for the various stakeholders.

The calculation of performance criteria was based on the formulae adopted by IWA where it is applicable and tailored to suit Jordan case as described in [13].

The data was analyzed to produce the needed indicators and comparison criteria as well as historical trends of enhancement. IWA indexes were used when applicable; PMU indicators which were based on IWA but tailored to suit Jordan were also used, some raw data (variables) were sometimes referred to in the comparison and analysis.

Most importantly, the Author of this research kept a focused eye on having the same definition of the indicators and criteria when conducting the analysis and comparison; similar information were compared (apple to apple comparison).

Aiming at clarifying the development of financial performance under different governance and management setups, a historical comparison and evaluation was conducted by comparing Amman utility performance during its operation by WAJ (year 1999), LEMA (2000-2006), and Miyahuna period as a corporate utility operated under commercial principles (2007-2013), The indicators and criteria variations and its trends have been discussed for possible indication and cause. To view Miyahuna financial performance in the regional and international context a second comparison focusing on benchmarking Miyahuna performance against regional and international utilities was conducted.

This paper conducts two performance assessment and comparison. Firstly, a historical performance assessment and comparison are conducted on the collected data, calculated performance criteria and indicators. Historical variations and trends are discussed for possible indication and cause during the different management styles (governmental, commercial and semi-commercial). Secondly, a comparison and benchmarking of Miyahuna performance against the performance of regional and international utilities are conducted using the available information on IBNET database and publications.

\section{RESULTS AND DISCUSSION}

Financial sustainability is a major planned target of MWI when decided to corporatize Amman utility, MWI planned and aimed at a viable, self-sustaining corporate, with modern commercial principles adopted in the management [14]. 


\subsection{Historical performance assessment}

The analysis and discussion of Miyahuna performance accomplished through analyzing the costs, revenues, and NRW. The performance resulted only from the commercialization process was shown by isolating the external factors affecting the performance and cannot be managed by Miyahuna. The effect of inflation as well as tariff increases during the periods analyzed has also been isolated. The inflation index calculated from the Consumer Price Index (CPI). In total, LEMA witnessed 20.6\% inflation while Miyahuna suffered from $52.6 \%$ up to year 2013 .

\subsubsection{Billed water unit cost both in nominal and real term}

The first cost indicator analyzed is the unit cost both in nominal and real terms calculated based on inflation rates using 1999 as a base year (Fig. 1). During LEMA period, the nominal unit cost of one cubic meter billed increased by $15 \%$ with significant reduction by $21 \%$ in 2003 and slight reduction in years 2001, but with average increase of $11.2 \%$ over the years 2002 and 2004-2006. During Miyahuna management period, the overall increase reached $45 \%$ with a decrease of $2.4 \%$ and $5.3 \%$ shown only in 2009 and 2010 respectively. In real value, LEMA managed to reduce the unit O\&M costs of one billed cubic meter by $8.5 \%$ despite the increase in 2002, 2004-2006 of $18.1 \%, 13.7 \%, 5.5 \%$ and $7.5 \%$ respectively. Miyahuna managed to reduce the same indicator over $2007-2013$ by $47 \%$ with only years 2007 and 2012,which showed increases of 1\% and 4.5\% respectively (Fig. 1). The discrepancy in 2002 and 2003 in both real and nominal values may be attributed to errors in the transfer of billing data from the old system Coboss II to X7 billing new System. The increase in 2012 and 2013 may be attributed to Miyahuna employees strike in 2012 and the relatively high costs Disi water (ground water aquifer located in south Jordan and pumped to Amman) which was put into partial operation in second half of 2013.

\subsubsection{Unit cost of system input (produced) one water cubic meter}

To clarify more the performance, unit cost of one produced (System input) cubic meter indicator was also analyzed in both nominal and real terms, and plotted in Fig. 2 During LEMA contract time, the nominal unit cost of one supplied cubic meter increased by $20.2 \%$ with slight cost reduction in years 2000, 2001, 2002 and 2004, but with sharp increases in 2003 and 2006. The average increase over LEMA period is $3.2 \%$. During Miyahuna management period the overall increase in nominal cost reached $38.4 \%$ with only 2009 and 2010 showed decrease of $0.7 \%$ and $4.8 \%$ respectively. Sharp increase happened in years 2007, 2008, 2011 and 2012 with percentages in the range of $10.5 \%-14.6 \%$. In real value, LEMA managed to reduce the unit O\&M costs of one supplied cubic meter by $4.5 \%$ despite the increase in $1999,2003,2005$ and 2006 of $5.3 \%, 10.9 \%, 0.4 \%$ and $2.2 \%$ respectively. However, Miyahuna managed to reduce the same indicator over $2007-2013$ by $49.5 \%$ with only year 2007 and 2009 that showed increase of $6.2 \%$ and $1.0 \%$ respectively.

\subsubsection{Revenue}

The study shows that LEMA managed to increase the billing and total revenues by $117 \%$, $152 \%$ respectively, while Miyahuna increased the billing and total revenues by $53 \%$ and $49 \%$.

The Unit revenue (billed and total) shows different trends (Fig. 3), and there is no explanation for the sharp increase in year 2002 except the drop of the quantity of billed water (high rates of Non-Revenue Water or errors in transforming the billing data from the old Coboss II billing system in use before 2003 to the new X7 billing system which resulted in 


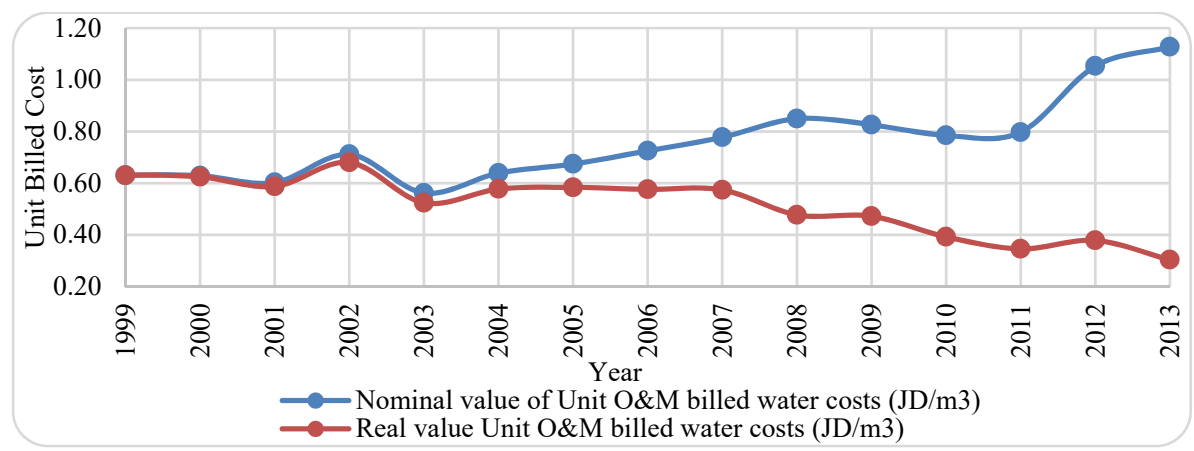

Figure 1: Amman utility nominal and real O\&M unit cost $\left(\mathrm{JD} / \mathrm{m}^{3}\right)$.

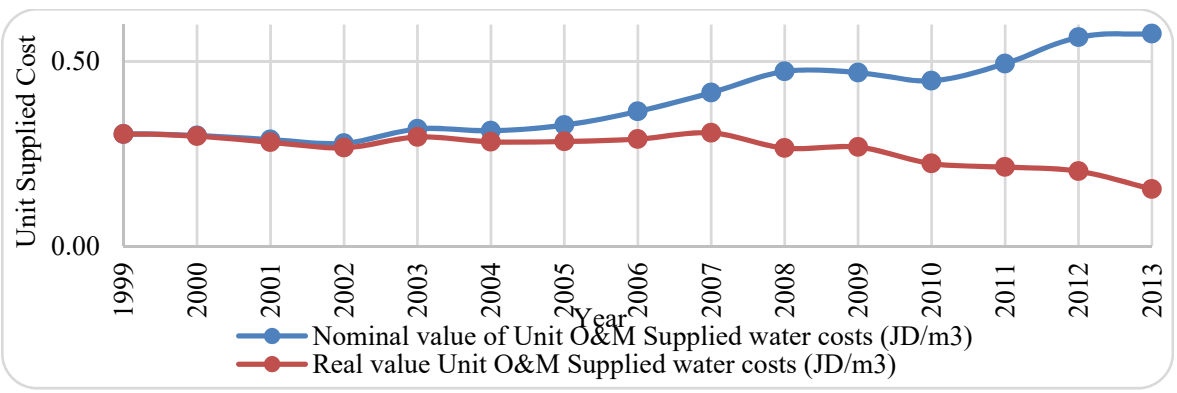

Figure 2: Amman nominal and real unit cost of supplied water $\left(\mathrm{JD} / \mathrm{m}^{3}\right)$.

paying back money to people objected on their invoices (Money was reimbursed to objection without changing quantities). The sharp increase in unit revenues in 2011 and later was partially resulted from the new tariff adopted in Januanry 2011. The same can be said to the slight increase in 2005 and 2006 as the government decided to increase the tariff by a lump sum amount to each water bill.

The isolation of tariff effect was done, as it is not completely within the jurisdiction of Miyahuna management. The results of the simplified calculation methodology to estimate the additional revenues generated by the tariff increases in years are presented in Table 1. Myahuna management again proved to progressing well and efficient in view of the increase in net billing revenues over its time (2006-2013) with the exception of 2012 where slight decrease is noticed. Again, the increased levels of NRW resulted from the employee's strike may explain the inefficiency of 2012. The unit billing revenues is not sensitive for the strike as it measures revenue generated from one sold cubic meter (Fig. 4). While the total unit revenue 2007 thru 2011 indicating a drop of non-billing revenues.

\subsubsection{Non-revenue water}

The significant importance of non-revenue water in Jordan come from the nature of scarcity of water resource and the marginal financial sustainability of the services [13]. The criteria used in evaluating the Non-revenue water included the NRW percentage. 


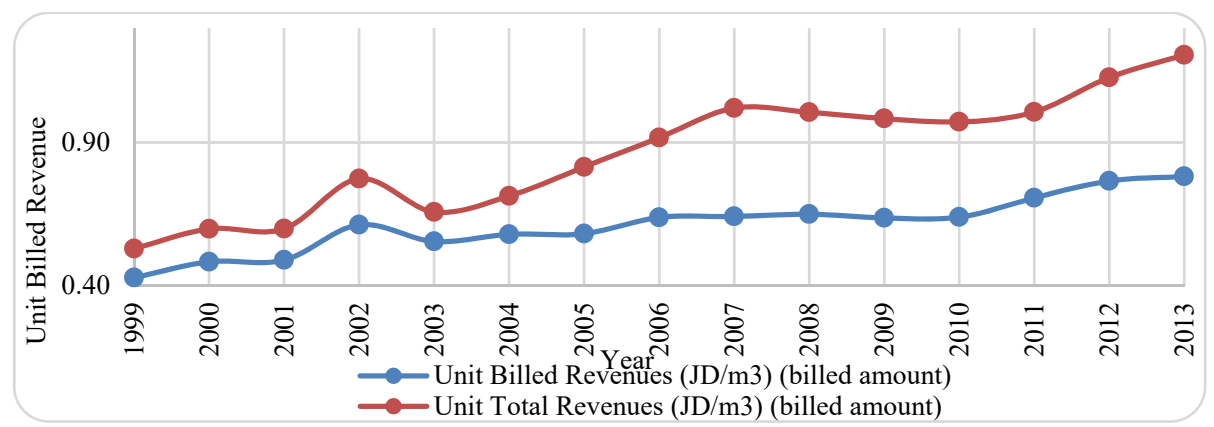

Figure 3: Unit billed revenues (JD/m3).

Table 1: Additional revenues as a result of tariff increase (MJD).

\begin{tabular}{|l|c|c|c|c|c|c|c|c|c|c|c|c|}
\hline & \multicolumn{9}{|c|}{ LEMA } & \multicolumn{10}{c|}{ Miyahuna } \\
\hline Year & 2002 & 2003 & 2004 & 2005 & 2006 & 2007 & 2008 & 2009 & 2010 & 2011 & 2012 & 2013 \\
\hline $\begin{array}{l}\text { Tariff } \\
\text { increase } \\
\text { 2002 }\end{array}$ & $\mathbf{0 . 7 2}$ & $\mathbf{0 . 9 5}$ & $\mathbf{1 . 0 4}$ & $\mathbf{1 . 0 6}$ & $\mathbf{1 . 2 3}$ & $\mathbf{1 . 3 7}$ & $\mathbf{1 . 5 0}$ & $\mathbf{1 . 5 2}$ & $\mathbf{1 . 6 1}$ & $\mathbf{1 . 9 0}$ & $\mathbf{1 . 8 4}$ & $\mathbf{2 . 1 0}$ \\
\hline & & & & & & & & & & & \\
\hline
\end{tabular}

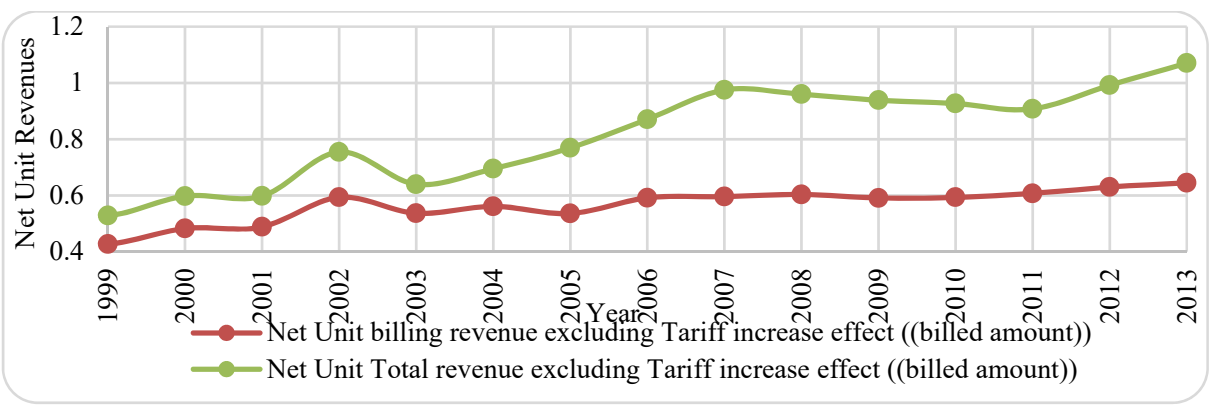

Figure 4: Unit total and billing revenue excluding tariff increase effect.

LEMA managed to reduce the NRW\% in its period from 52\% in 1999 (Base Year) to 47\% in one year then to $43 \%$ in its remaining period (until 2006), while Miyahuna reduced it from $43 \%$ (year 2006) to almost $34 \%$. The NRW quantity amounted to 351 million cubic meters with yearly average of $50 \mathrm{MCM}$ when LEMA was operating the utility, while it reached 365 Million meter cube with yearly average of 52 MCM during Miyahuna operational period (Fig. 5).

As depicted in Fig. 5, the nominal value of accumulated revenues (money) lost due to NRW totaled 199 MJD and 252 MJD during LEMA and Miyahuna operational periods respectively. The sharp increase and sudden drop in revenue loss during 2002-2003 can be interpreted as resulting from the change of billing system from Coboss II to X7. Fig. 5 also indicates that starting from 2006 a steady decrease in revenue losses was achieved until 
reaching only 30MJD. The yearly reduction of NRW\% during 2006-2011 averaged more than 2\% per year exceeding the target set for Miyahuna in the Assignment and Development Agreement. For the whole Miyahuna operational period, the average yearly reduction is $1.2 \%$ satisfying the target and complying with MWI policy regarding NRW reduction.

Comparing the recorded NRW\% trends in LEMA and Miyahuna time, reveal that the achieved rate of reduction in NRW\% is higher for Miyahuna compared to LEMA (Fig. 5). The explanation of the discrepancy in years 2002 and 2003 is explained above. It is worth mentioning that the average NRW\% of the two years is $46.7 \%$ which if corrected to rectify the errors in data transfer from Coboss II to X7 is in line with LEMA achievement in its period. Moreover, the years 2011 and 2012 showed trend values which can be explained by changing the billing cycle starting from January 2011 where monthly billing was implemented and, resulted in shifting two months of water that should be billed in 2010 to 2011. This increased the amount billed in 2011 and thus reduced NRW in 2011.

In 2012 , the NRW has substantially risen to $37.7 \%$ (by $8.1 \%$ ). An attempt to understand the reason for this sharp increase was done by analyzing both components of non-revenue water (Apparent losses and Real losses), and understanding correlation between these changes and the social unrest happened during 2012 in the context of "Arab Spring". In the high correlation between Miyahuna employees' strikes happened in 2012 and the associated resonse of Miyahuna were the main reasons for this drop in performance.

The NRW also showed increase in 2013 if compared to the trend of years 2006-2010. This can be explained by the increase in system input by $18 \%$ from DISI water in second half of the year. The increased supply Index affected the apparent and physical losses from pipes as water staying longer in pipes increases leaks amount. It also reduces the accuracy of water meter readings as the type of water meter used in Amman is Class B. Class B meters are sensitive to low flow resulting in increased in-accuracy when the flow duration increases.

\subsection{Miyahuna financial performance compared to international norms}

The most significant comparison was between Miyahuna and the overall international utilities reporting to IBNET. The number of international utilities reported to IBNET database is significant but the size of utilities varies from small utilities of less than 5000 customers to more than a million customers. This suggests using the median and the unweighted average in the evaluation. The weighted average cannot be calculated due to

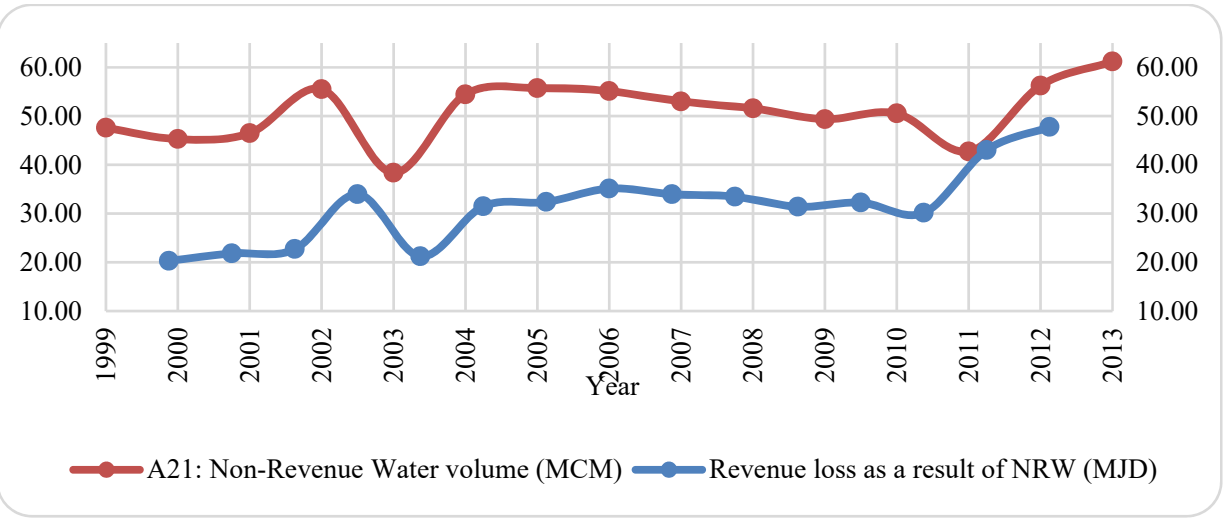

Figure 5: Amman NRW volume (MCM); loss of revenue (MJD). 
unavailability of utilities number of customers. In the part, international norms, regional and utilities similar to Miyahuna in size (Band) was compared with Miyahuna achievements over the past years.

\subsubsection{Operation and maintenance unit costs of water}

The IBNET Indicator Operational Unit Cost of Water and Wastewater (Billed as well as Produced water) was used to conduct the comparison.

Miyahuna billed water and wastewater operational unit cost are higher than the international averages as well as the average of utilities similar to Miyahuna. Miyahuna billed unit cost was on average 140\% of the international average during 2007-2011 (Fig. 6), and $160 \%$ of the band average billed unit cost for the years 2007-2013. On the regional level the percentage reached 190\% 2007-2010. In year 2013, Miyahuna billed unit cost was 160\% of the average billed cost of utilities similar to Miyahuna.

The unit cost of billed cubic meter of water is sensitive to different factors available in Jordan, especially in Miyahuna case. The elevation difference to which water is pumped is about 1600 meters. Electricity prices went up after the liberalization of fuel prices and the interruptions of the Egyptian gas flow to Jordan. The prices of the PPP projects of Disi and AsSamra wastewater treatment plant charges; Moreover, high rates of Non-revenue water accounts in addition to the PPP projects of Disi and As_Samra wastewater treatment plant charges. The financial crisis of 2008 might affected all utilities cost on both local and international levels. Those factors also affect the unit cost of produced water. As seen in Fig. 7, Miyahuna Unit cost of produced water is also higher than those of the region and band, but the difference is less compared with that for the billed water.

\subsubsection{Revenues}

Miyahuna Operation Unit Billed Revenues compared to international avarege norms all measured in $\left(\mathrm{JD} / \mathrm{m}^{3}\right)$ is presented in Fig. 8. Miyahuna Unit Billed Revenue in 2013 is $170 \%$ of the average unit billed revenue generated by band utilities. The avarege of Miyahuna unit billed revenue for the years $2007-2013$ is $140 \%$ of the un-weighted average of international unit billed revenue . The arithmetic mean of Miyahuna unit operation revenue during 20062010 was $1.0 \mathrm{JD} / \mathrm{m}^{3}$, while it is $0.9 \mathrm{JD} / \mathrm{m} 3$ for international utilities, 0.6 for the band utilities and $0.3 \mathrm{JD} / \mathrm{m} 3$ for regional utilities for the same period. Miyahuna unit billed revenue is higher than the median of the international utilities unit revenue, this suggests that Miyahuna billing revenues is within the third quartile of the international utilities unit revenues.

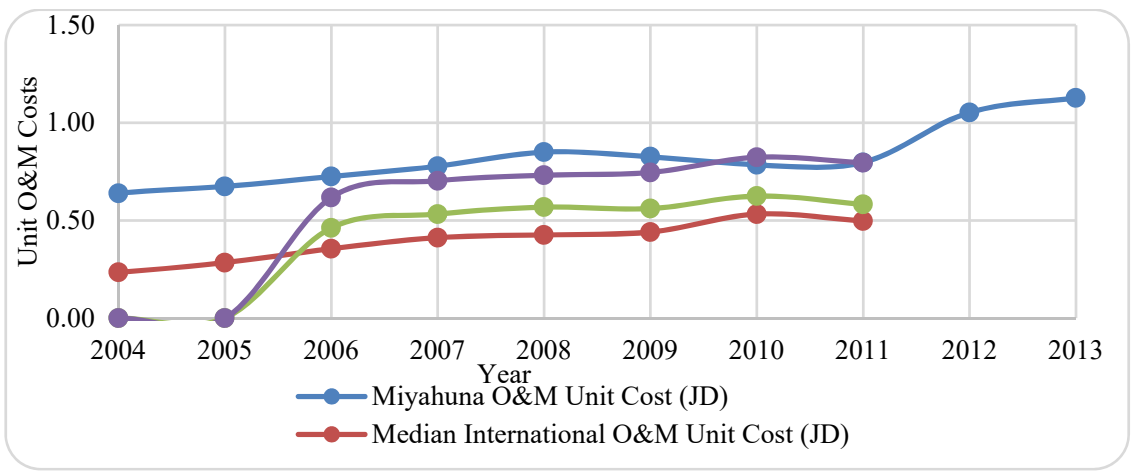

Figure 6: Billed operational unit cost versus international norms (JD/m3). 


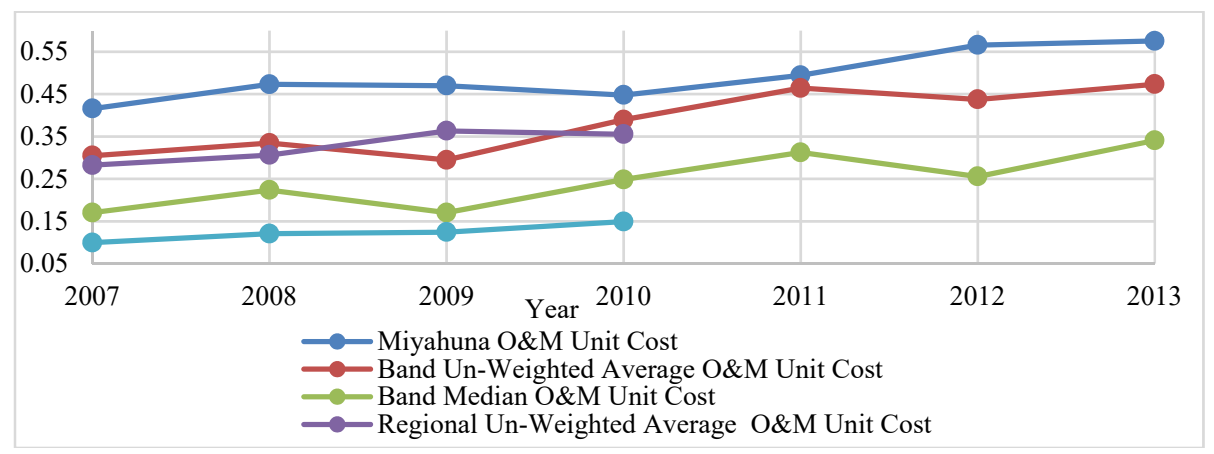

Figure 7: Produced operational unit cost versus regional and band norms.

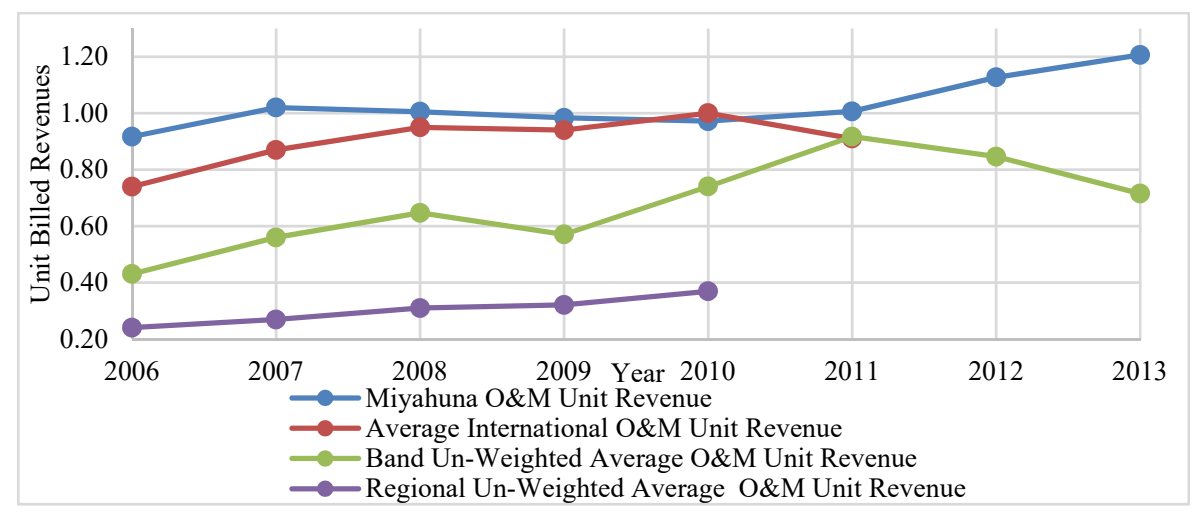

Figure 8: Unit billed revenues compared to international norms (JD/m3).

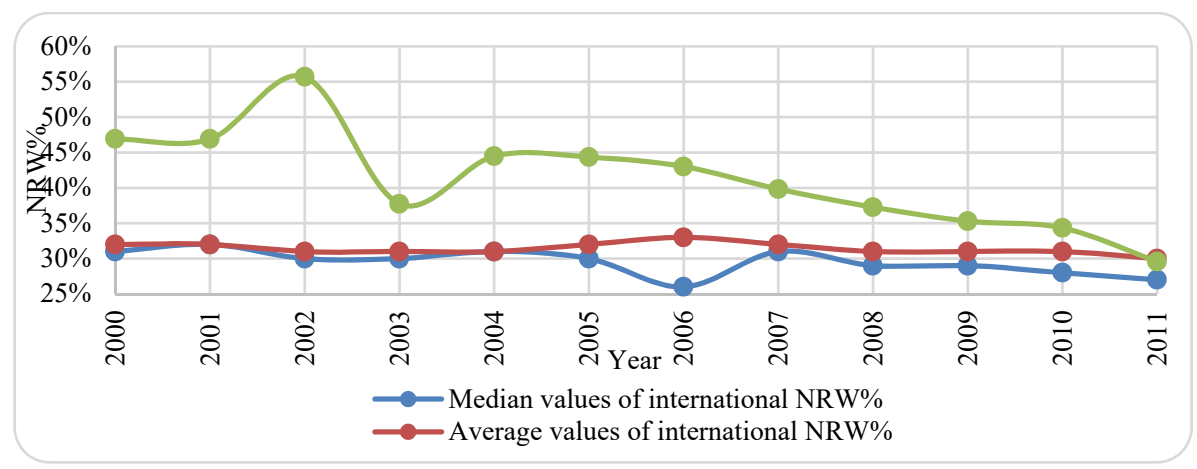

Figure 9: Miyahuna NRW\% compared to international norms.

\subsubsection{Non-revenue water}

Fig. 9 presents the NRW\% median and un-weighted average of international utilities and Miyahuna NRW\%. It is worth mentioning that the standard deviation of NRW\% in the 
studied period varied from $17 \%$ to $22 \%$ with average standard deviation of $19 \%$ indicating wide variations of utilities NRW\%.

Fig. 9 indicates that Amman utility achieved progressive reduction of NRW\%. It managed to reduce NRW\% from almost twice the international norms to almost being within or equaling the average and median of international NRW\%. The median international NRW\% over years 2009-2011 was 28\%; the un-weighted average was 31\%, while Miyahuna achieved $33 \%$ in average. The credibility of the data generated from IBNET may be questioned for reliability due to: the number of utilities in the region who reported its NRW\% criteria is limited in years 2000 through 2004, Although limited in number, some utilities reported NRW\% of more than $100 \%$, and some utilities reported values of NRW\% that changes dramatically from one year to the other.

\section{CONCLUSION}

The Paper concludes that application of the corporatize model was successfully applied for Amman utility and can be applied and replicated to other utilities in its endeavor for better and sustainable services. Miyahuna performance in the long term reveals positive trends in most of the evaluated criteria specially non-revenue water, and other financial sustainability. The financial position of Miyahuna has also been ranked as satisfactory as evident from the indicators explored despite the challenges faced, and compered to international, regoinal, and band utiliies. Achieving the revenues trigger the need for exploring and studying the affordability limits of Miyahuna customers and also to research their willingness to pay in order to achieve the revenues trigger. It is recommended to establish benchmarking system in Jordan water sector and to conduct further studies concerning affordability and willingness to pay. Non-revenue water reduction plan is a priority recommendation.

\section{REFERENCES}

[1] Idelovitch, E. \& Ringskog, K., Private Sector Participation in Water Supply and Sanitation in Latin America. The World Bank, 1995.

[2] Prasad, N., Privatisation results : Private sector participation in water services after 15 years, 24, (6), pp. 669-692, 2006.

[3] Department of Treasury and Finance, Corporatisation principles for local government business activities, 1998.

[4] Wieriks, M., Performance Assessment of water sectors - methods and considerations for application, pp. 1-8, 2011.

[5] Kiser, LL. \& Elinor, O., Three worlds of action: A metatheoretical synthesis of institutional approachestle. Strategies of Political Inquiry, 1982.

[6] Roche, P.A., Le Fur, S. \& Canneva, G., Improving Performance of Water and Sanitation Public Services. Marseilles, 2012.

[7] Alegre, H. \& Coelho, S.T., Infrastructure asset management of urban water systems. Water Supply System Analysis - Selected Topics, pp. 1-26, 2009.

[8] Alexander, D., Van den Berg, C. \& Macheve, B., The IBNET Water Supply and Sanitation Blue Book 2014: The International Benchmarking Network for Water and Sanitation Utilities Databook, World Bank Group: Washington DC, 2014.

[9] Water, A., Transformation of water organizations, From administrative hierarchy beyond marketization, 2008.

[10] World bank, The Hashemite Kingdom of Jordan Water Sector Review, Amman, 1997.

[11] Water, L., Authority of Jordan (WAJ) and Jordan Water Company - Miyahuna, Assignment and Development Agreement, Amman, 2007. 
36 Water Resources Management IX

[12] IBNET, International Bank for Reconstruction and Development (IBNET) / Benchmarking, Online. http://www.ib-net.org/en/production/?action=benchmarking. Accessed on: 6 Dec. 2014.

[13] Ricketson, C., Final Report Performance Measurements and Benchmarking Table, Amman, 2004.

[14] United States Agency of International Development (USAID), Amman Water Management/Commercialization Assessment Phase Two Report: Feasibility Analysis of New Company, 2006. 